\title{
ESCOLA SISTÊMICA: RELATO DE UMA PRAXIS NO SENAI DE JOINVILLE-SC
}

\author{
Marlow Rodrigo Becker Dickel ${ }^{1}$ \\ Nilton Manoel Lacerda Adão² \\ Silvio Luis de Sousa ${ }^{3}$
}

\begin{abstract}
RESUMO
O relato objetiva mostrar alguns métodos do projeto intitulado Escola Sistêmica, realizado no último ano de um Curso Técnico de Informática no SENAI de Joinville - SC. O projeto apresenta um processo de ensino e aprendizagem com característica interdisciplinar com vias de transdiciplinaridade. Como proposta, nesse artigo, elencouse os principais métodos alinhados à forma de abordagem para mostrar a prática com alguns resultados observados por estudantes e professores. Esse texto apresenta um relato de experiências dos últimos cinco anos letivos. Para tanto, utilizou-se a pesquisa participante considerando a experiência dos autores como professores. Como evidência aplicou-se entrevistas não diretivas para indicar a percepção dos estudantes envolvidos no projeto no ano de 2011. Também considerou-se a opinião de ex-estudantes que ainda mantém contato com os professores. Como resultado deve-se destacar a compreensão atual do método constituído e seus resultados. Esses, por sua vez, por ser tratar de uma abordagem sistêmica consideram construções com níveis de complexidade e em constante transformação.
\end{abstract}

Palavras-chave: Escola Sistêmica. Curso Técnico em Informática. Processo ensino e aprendizagem.

\footnotetext{
${ }^{1}$ Graduado, e-mail: marlow.dickel@sc.senai.br

${ }^{2}$ Mestre, e-mail: niltonlacerda@sc.senai.br

${ }^{3}$ Especialista, e-mail: silvio.sousa@sc.senai.br
} 


\title{
1 INTRODUÇÃO
}

\author{
"Cedo ou tarde você vai perceber, como eu, que há uma diferença entre \\ conhecer o caminho e percorrer o caminho". (Morpheus, personagem do \\ filme Matrix).
}

Na etimologia, currículo origina-se do latim currèreque que significa correr ou lugar onde se corre, ou seja, curso de uma corrida (ESLABÃO, 2006).Um ponto a ser observado é que estudantes que participam dessa "corrida" não largam com as mesmas características ou condições. Da mesma forma a compartimentação curricular por meio de disciplinas pode resultar na não conexão por parte de estudantes e professores dos conhecimentos trabalhados resultando em habilidades e atitudes inadequadas às competências almejadas. Considerando diferentes formas de interpretação do que venha a ser competência, optou-se por reconhecer, nesse relato, a integração das três formas de abordagens identificadas por Zarifian (2001) da primeira destaca-se, a necessidade de se tomar iniciativa diante de situações do trabalho, da segunda, o entendimento prático para agir nas situações possibilitando a ampliação dos conhecimentos, da terceira, a faculdade de mobilizar uma rede de atores em uma mesma situação considerando que as ações em uma realidade complexa excedem a capacidade individual.

O projeto Escola Sistêmica teve início no Curso Técnico em Informática no Serviço Nacional de Aprendizagem Industrial (SENAI) de Joinville - SC, em 2007, em que observava-se uma dissonância com a realidade idealizada pelas competências já apresentadas que, no caso deste artigo, servem como ponto de partida para a construção do conhecimento com base em competências. Mesmo em um currículo considerando uma integração sistemática dos conteúdos, nos Trabalhos de Conclusão de Curso, os estudantes apresentavam dificuldades de associar diferentes conhecimentos para agir em uma realidade de trabalho.

Considerando as competências organizacionais (funções, processos, áreas) e individuais (perfil adequado às exigências do mercado), e, principalmente as características culturais e "bagagem teórica e prática" dos estudantes, observou-se a necessidade de integrar as atividades de forma contextualizada para promover um processo de ensino e aprendizagem mais adequado à abordagem construtivista francesa de educação baseada em competências. Segundo Nunes (2007), elas identificam trabalhadores capazes de responder ao processo produtivo de forma eficiente melhorando situações de trabalho. Para tanto, o processo pedagógico deve ser considerado de forma contextualizada.

Muitas eram as dúvidas; e algumas poucas certezas serviram como base para tentar modificar a realidade: "não se desenvolve software sozinho" e o conhecimento deveria ser trabalhado de forma "sistêmica e não sistemática". O desafio de encontrar a melhor abordagem indicou a viabilidade de trabalhar com situação-problema. O quadro a seguir procura mostrar diferentes abordagens que podem ser confundidas como sinônimos, mas para o entendimento do caso apresentado são diferenciadas para elucidar a compreensão da proposta. 
Quadro 1: Diferentes abordagens de aprendizagem

\begin{tabular}{|l|l|}
\hline $\begin{array}{l}\text { Aprendizagem baseada } \\
\text { em problemas }\end{array}$ & $\begin{array}{l}\text { Deve-se trabalhar temas essenciais para cumprimento } \\
\text { do currículo necessário para exercer a profissão. Há uma } \\
\text { sequência de problemas a serem estudados e com o } \\
\text { término de um, inicia-se o estudo de outro. Os problemas } \\
\text { são elaborados por uma comissão designada para esse fim. }\end{array}$ \\
\hline $\begin{array}{l}\text { Metodologia da } \\
\text { problematização }\end{array}$ & $\begin{array}{l}\text { Os problemas são extraídos da realidade a partir da } \\
\text { observação feita pelos estudantes. }\end{array}$ \\
\hline $\begin{array}{l}\text { Abordagem por } \\
\text { situações-problema }\end{array}$ & $\begin{array}{l}\text { Coloca o estudante diante de uma série de decisões a } \\
\text { serem tomadas visando o alcance de um objetivo escolhido } \\
\text { por ele ou que lhe foi proposto. }\end{array}$ \\
\hline
\end{tabular}

Fonte: Nunes (2007)

Ponderando o ideário inerente ao perfil do profissional de um Curso de Informática no SENAI de Joinville - SC, optou-se pela abordagem relacionada à resolução de situaçõesproblema relacionadas à transformação de uma realidade. Essa necessidade estava alinhada com a necessidade de mudança, observada pelos professores e já difundida na teoria.

Embora tenha se destacado, a partir de 1960 em discussões sobre o distanciamento entre o ensino e a realidade do trabalho, a educação baseada em competências tem sua origem nos anos de 1920, nos Estados Unidos da América (NUNES, 2007). Um nome de referência para o modelo estadunidense foi David McClelland que indicava que os testes acadêmicos não garantiam melhor desempenho no mundo do trabalho, nem sucesso na vida (NUNES, 2007). Nesse país, na década de 1970 surgiu o movimento denominado Ensino Baseado em Competências (NUNES, 2007). Um exemplo é o estudo de Nagel e Richman (1976) de California State University, que considera como Ensino para Competência como um programa flexível e individualizado. Assim os professores poderiam trabalhar no próprio ritmo sem receio de fracasso por meio de um programa de trabalho com base em objetivos de ensino. Esses autores enfatizam um ensino individualizado considerando que estudantes aprendem em tempos diferentes.

\footnotetext{
Deve existir um meio de lidar com o obstinado, o desinteressado, o aluno médio e com o estudante talentoso em minha classe. Deve existir uma maneira de maximizar meu tempo com os alunos e minimizar o tempo gasto com dar notas, controlar disciplina, expor a matéria e bancar o polícia. Precisa haver uma forma de anular a pressão que eu e meus alunos sofremos e de fazer da aprendizagem uma experiência cheia de êxtase. (NAGEL; RICHMAN, 1976, p. 1, grifo nosso)
}

Mesmo que, a base teórica das atividades que serão apresentadas estarem mais alinhadas ao modelo construtivista francês, da abordagem estadunidense, deve-se destacar o que se vivenciava: o modelo de provas era inadequado e aulas expositivas não atendiam aos interesses dos estudantes. 
Considerando as questões e questionamentos que nortearam o que podia ser identificado como uma mudança de paradigma, optou-se pelos Trabalhos de Conclusão de Curso como base para novas ações. No decorrer dos cinco anos, procurou-se construir o que hoje é denominado de "Escola Sistêmica". Para limitar as discussões, relatos históricos só serão apresentados quando para validar algum dos métodos, assim como a base teórica. Nesse sentido, este artigo objetiva apresentar alguns métodos balisadores das ações desenvolvidas pelo Curso Técnico em Informática de Joinville no SENAI de Joinville - SC.

\subsection{Método: relato de experiências}

Este artigo configura-se no relato de experiências, nesse contexto, apresentam-se informações considerando o que Magalhães (2005) identifica como experimentalismo representando experiências de forma metódica, apesar da observação nem sempre ser sistemática. Assim sendo, é necessário um fundamento conceitual, que pode ser até mesmo implícito, mas que negue um pressuposto puramente empirista. Para elucidar esta questão apresentam-se algumas bases teóricas resultantes de pesquisa bibliográfica que segundo Da Silva, Cervo e Bervian (2007) serve para explicar um problema a partir de referências teóricas publicadas na forma de livros, artigos, dissertações e teses. Mesmo assim, como relato de experiência, esse artigo consiste na apresentação do vivido e percebido por parte dos autores como integrantes do processo. É nesse sentido, que as bases teóricas apresentadas são caracterizadas por uma necessidade de fundamentar teoricamente ações vivenciadas no processo de ensino e aprendizagem. Para tanto, na redação deste artigo, optou-se por detalhar algumas práticas, que foram se constituindo nos últimos cinco anos, realizadas em turmas do Segundo Ano do Curso Técnico em Informática no SENAI de Joinville - SC. Para evidenciar os resultados apresentam-se relatos dos estudantes que participaram do projeto ano de 2011. Ao todo foram entrevistados 48 estudantes, seguindo o método de entrevista não diretiva que, segundo Severino (2007), serve para colher informações a partir do discurso livre. Visando garantir a veracidade dos comentários acordou-se que não seriam indicados os nomes dos entrevistados reconhecendo-se que a cientificidade está nas informações e o informante é quem dá legitimidade por participar do processo. Coube a cada entrevistado responder de forma livre a uma única pergunta: o que você achou do método de ensino aplicado na Escola Sistêmica? Com base nos relatos dos estudantes, foi possível analisar os métodos empregados no processo ensino e aprendizagem. Também utilizou-se informações de ex-estudantes que, por e-mail e pessoalmente, ainda mantém uma relação de proximidade com os professores indicando a realidade do mercado de trabalho e "trocando experiências".

Como os pesquisadores também são sujeitos no processo, quanto à sua modalidade, a pesquisa pode ser identificada como participante onde, segundo Severino (2007), o pesquisador compartilha a vivência dos sujeitos e interage com ele em todas as situações.

Como principal limitação pode-se indicar que a riqueza de informações, sejam elas negativas ou positivas, não podem ser apresentadas em todos os seus detalhes em formato de artigo. Mesmo assim, o esforço por parte dos autores está na procura de 
apresentar de maneira mais sistemática, para melhor compreensão, ações que se configuram como sistêmicas com o cuidado de não desconfigurar a essência da prática.

\section{O PROJETO ESCOLA SISTÊMICA}

\subsection{Apresentação}

O nome "Escola Sistêmica" tem base em discussões referentes à práticas e pensamento sistêmico focando questões que, segundo Vasconcellos (2002), configuram um paradigma emergente da ciência que, entre outras coisas, considera o não reducionismo, padrões interconectados, relações, imprevisibilidade, complexidade, múltiplas verdades e transdisciplinaridade. A problemática inicial do Curso Técnico em Informática em Joinville era a de fazer os estudantes observarem, compreenderem e agirem considerando as relações e interações entre Unidades Curriculares abordando o currículo do curso como um todo. Para tanto, fez-se necessário unir as disciplinas em detrimento de algo maior. Para melhor compreensão da ação, pode-se citar a definição de multi. Pluri, inter e transdiciplinaridade:

Quadro 2: Formas de abordagem

\begin{tabular}{|l|l|}
\hline Multidisciplinaridade & $\begin{array}{l}\text { As disciplinas são postas em conjunto, mas sem necessidade de } \\
\text { interação entre as mesmas, tendo como exemplo disciplinas como } \\
\text { Música e Biologia sendo vistas em um mesmo momento de um curso. }\end{array}$ \\
\hline Pluridisciplinaridade & $\begin{array}{l}\text { Há a complementação entre as disciplinas, que interagem entre si, } \\
\text { mas sem maior controle ou organização, como conhecimentos em } \\
\text { Geografia de uma região podem ajudar a entender melhor sua História, } \\
\text { por mais que não seja sempre assim. }\end{array}$ \\
\hline Interdisciplinaridade & $\begin{array}{l}\text { As disciplinas precisam uma da outra, se complementando e tendo } \\
\text { igual importância para que um objetivo seja alcançado. Pode-se ter } \\
\text { como exemplo a montagem de um móvel seguindo seu manual de } \\
\text { instruções: são várias as tarefas (disciplinas), mas fora de ordem não } \\
\text { se chegará ao produto ideal. }\end{array}$ \\
\hline Transdisciplinaridade & $\begin{array}{l}\text { Já não se faz mais divisão entre as disciplinas, mas objetivos são } \\
\text { definidos para se chegar a um resultado final, como por exemplo é } \\
\text { o conhecimento fisioquímico, que combina as áreas de Física e } \\
\text { Química para uma abordagem mais ampla de algumas interpretações } \\
\text { e observações. }\end{array}$ \\
\hline
\end{tabular}

Fonte: Adaptado de Amboni et. al. (2012), Lavaqui e Batista (2007) e Mangini (2009)

A figura a seguir mostra a representação gráfica das formas de abordagem já descritas. 
Figura 1: Representação gráfica das formas de abordagem

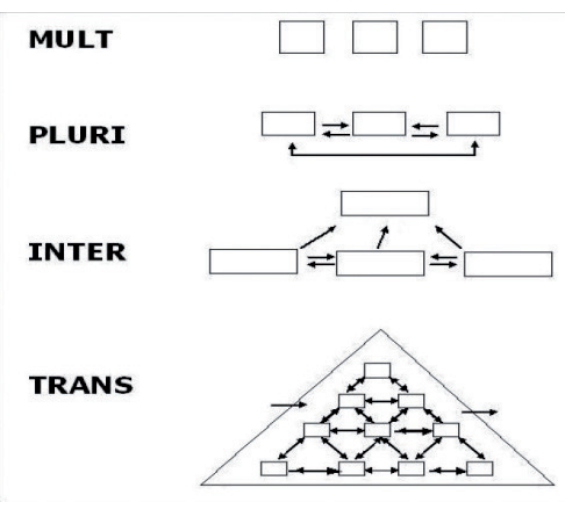

Fonte: Silva (2001 apud AMBONI et. al., 2012)

Compreendendo a importância das Unidades Curriculares do Curso, assim como as tendências para um novo paradigma científico, a figura a seguir serve para mostrar o sistema em que se insere o projeto, considerando suas múltiplas interações destacando a complexidade das relações, sistemas de interesses e diálogos entre conhecimentos.

Figura 2: Sistema Escola Sistêmica

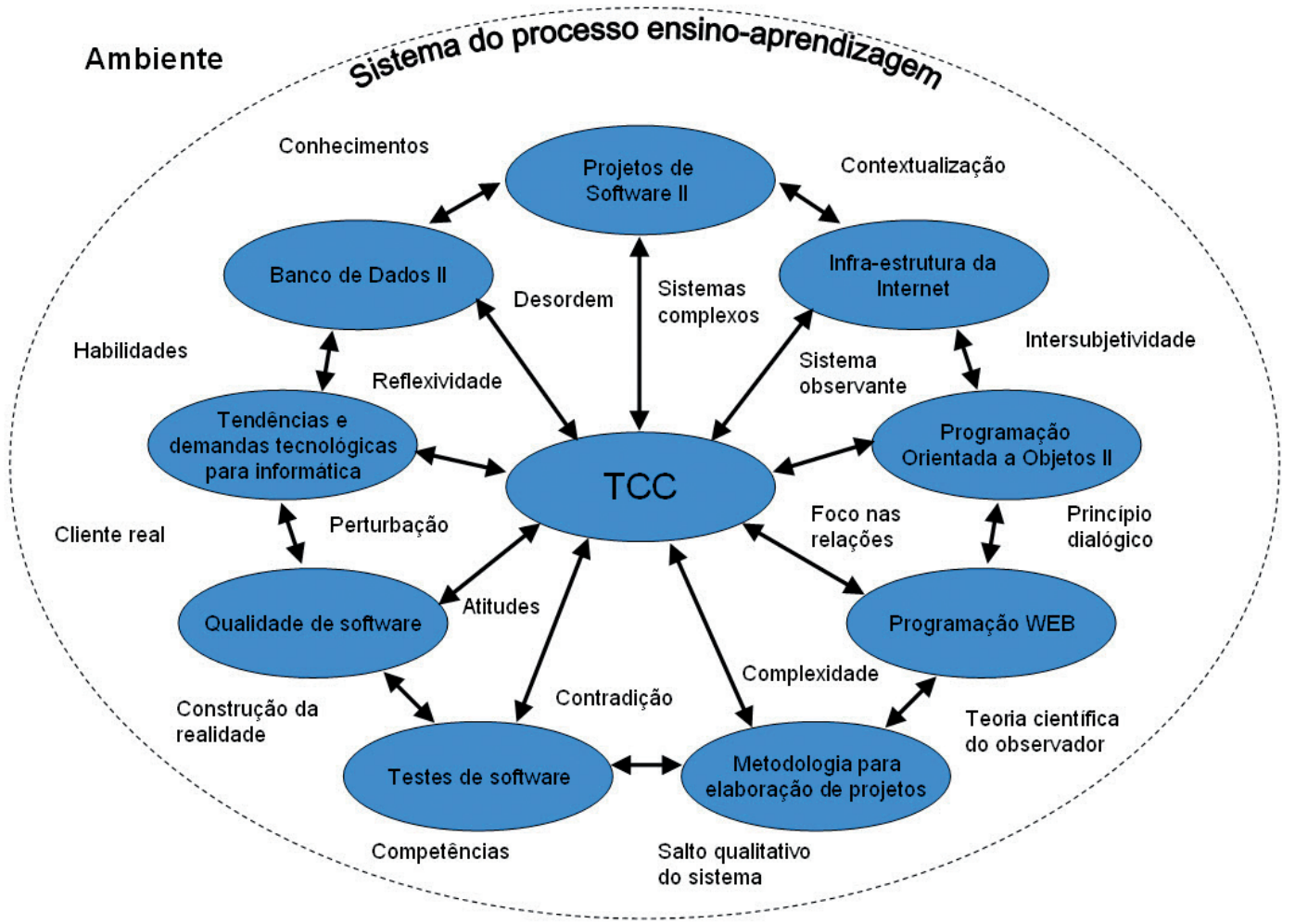

Fonte: Dos autores ( com base no currículo do curso e Vasconcellos,2002) 
Tendo em vista que o curso possui uma matriz curricular a ser seguida, e que no fim do processo de ensino é necessário que o estudante tenha adquirido o conhecimento nele pressuposto quanto a todas as disciplinas nela dispostas, vê-se que a Escola Sistêmica faz o uso de uma abordagem interdisciplinar tendendo à transdisciplinaridade. Como indicação teórica considera-se a pertinência da interdisciplinaridade que segundo Mangini (2009), institucionaliza novos modelos de educação e formação para os trabalhadores como também das organizações abrindo caminho para conhecimentos como pró-atividade, inteligência, capacidade de resolver situações-problema, entre outros.

Na prática, o projeto aplica-se ao último ano de um curso de dois anos (não utiliza-se no discurso o ensino como semestral por considerar o processo como anual e sistêmico) em que os estudantes devem desenvolver um software para uma situação real. Para tanto, há a existência de um cliente real que resulta no final do curso no Trabalho de Conclusão de Curso. Como requisito final os estudantes devem ter construído um software considerando também a elaboração de toda a documentação teórica e prática do produto. Nesse "caminhar" (mais indicado quando considera o tempo de compreensão dos estudantes sendo diferente da "corrida" na origem da palavra currículo) os estudantes lidam com todas as situações relacionadas ao desenvolvimento do software que considera a necessidade de compreender uma situação real, indicar soluções e chegar a um produto final que atenda aos interesses do cliente ${ }^{1}$ e aos conhecimentos, habilidades e atitudes requeridos pelo perfil indicado pelo currículo do curso.

Para o sucesso do projeto, que inicialmente parte da desconstrução do modelo tradicional de ensino, os estudantes deixam aulas tradicionais e passam a ter treinamentos coletivos de tempo reduzidos, mediações em pequenos grupos e orientações individualizadas. A preocupação, mesmo em temas mais objetivos é mostrar a sua aplicação na prática. Um exemplo cabível nesse momento é a constituição da logo do projeto apresentada na figura a seguir.

Figura 3: Árvore do Conhecimento construídas pelos estudantes

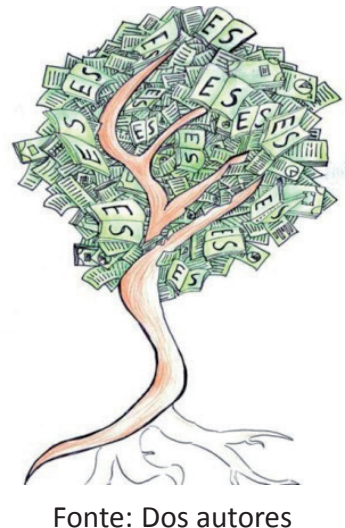

\footnotetext{
${ }^{1}$ No processo de desenvolvimento de TCCs do referido curso é necessário a existência do "cliente" para que o aluno desenvolva sua pesquisa aproximando-se das realidades e necessidades do mercado. Entretanto, é valido relatar que não existe relação comercial, os estudantes desenvolvem os softwares de forma voluntária responsabilizando-se em entregar o produto final (software)
} 
A Árvore do Conhecimento foi criada pelos próprios estudantes como resultado de um treinamento sobre a criação de logomarca, sendo esse idealizado pela necessidade das equipes personalizarem seus softwares e, em alguns casos, criarem a logomarca da empresa de seu cliente. Como defesa conceitual apresentada pelos estudantes, "ela representa a construção de conhecimentos, essenciais para a vida e necessários para a sobrevivência dos seres. Os livros demonstram as informações agregadas durante ela, sendo que cada um deles representa um conhecimento; já a árvore é a interação dos mesmos, onde os troncos crescem juntos formando uma "bagagem" de informações. Como se pode ver, o corpo da árvore forma as iniciais de Escola Sistêmica. Vendo pela forma de Escola Sistêmica, a escolha da árvore como base para o logotipo busca representar a vida que a cada dia nos traz uma nova experiência e um novo aprendizado."

A construção da logomarca, assim como a sua defesa conceitual, foi realizada por uma equipe de trabalho, socializada e discutida com o grande grupo e validada para ser a identificação visual do projeto. Esta atividade foi realizada em 2011 e em 2012 foi reavaliada e aprovada pelo novo grupo que aprimorou o desenho para melhor qualidade visual.

\subsection{Alguns métodos do processo ensino e aprendizagem}

\subsubsection{Pontos de checagem}

Pontos de checagem (Checkpoint) é um método utilizado em engenharia de software para se ter controle sobre as diferentes fases do desenvolvimento considerando a qualidade do processo. Destaca-se que os estudantes devem desenvolver competências, habilidades e atitudes do ponto de vista técnico em construção de projetos de software ,bem como, na sua programação. Os pontos de checagem são os momentos de aferição do desenvolvimento a partir de atividades propostas para ambas às instâncias.

Figura 4: Ponto de checagem e troca de experiências

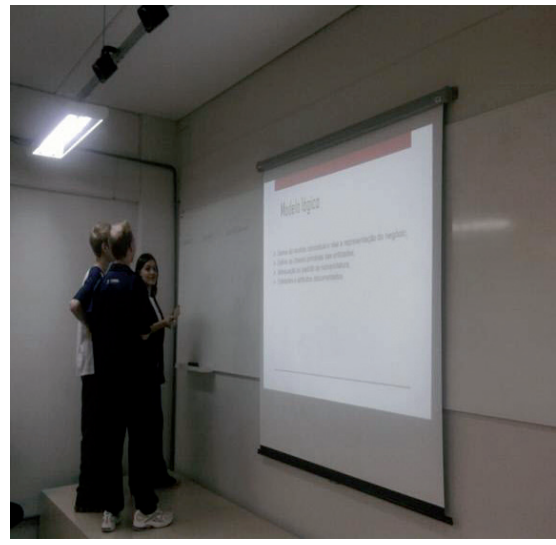

Fonte: Dos autores 
O ponto de checagem da figura acima, realizado em um dos auditórios da instituição, com a presença de todos os estudantes da turma, teve como objetivo a explanação da compreensão dos integrantes de uma equipe sobre conceitos em Banco de Dados, onde eles demonstraram através de uma apresentação eletrônica e do uso do quadro como foi realizada a criação do Modelo Lógico do Banco de Dados que eles utilizaram em seu projeto. Como a discussão do conteúdo é feita entre os próprios estudantes, com apenas o auxilio e direcionamento dos professores, se cria um ambiente mais informal e com "menos pressão" para a construção do conhecimento. Um conceito utilizado, nesse e em todos os outros momentos, é o de feedback, que para Tonsig (2008), de forma geral, pode ser reconhecido como retroalimentação, retroação, servomecanismo ou realimentação impondo correções ao software de forma equilibrada. A mesma abordagem é dada ao processo de ensino e aprendizagem considerando feedbacks negativos e positivos para retroalimentação com base no conceito de homeostasia, que segundo Tonsig (2008), quando alguma parte do sistema sai do equilíbrio deve-se acionar um mecanismo para restaurar a normalidade do funcionamento. A imagem a seguir mostra uma pré-banca, ponto de checagem onde simula-se uma banca de apresentação de TCC.

Figura 5: Pré-banca

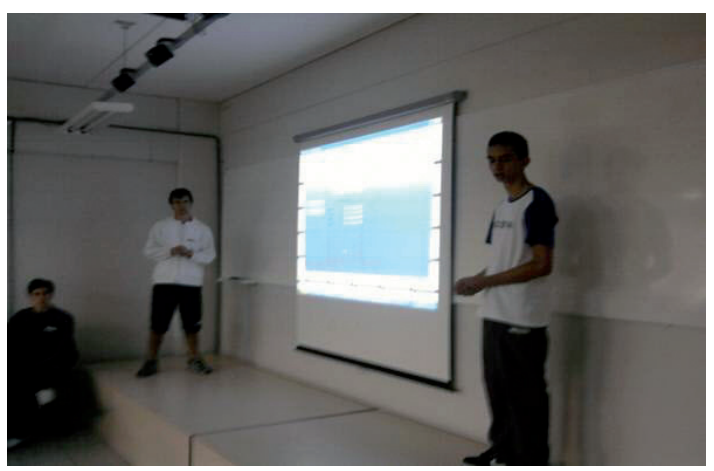

Fonte: Dos autores

Nas pré-bancas os estudantes apresentam as fases dos seus estudos para os professores e, quando houver disponibilidade e for plausível, para o próprio cliente, de uma maneira mais formal, para que eles possam se ambientar com a situação que enfrentarão na banca final. Aqui são tomadas algumas decisões e, se necessário, são solicitadas alterações para corrigir ocasionais desvios de foco no andamento dos trabalhos. Trabalha-se também o conceito de sinergia nas equipes, partindo-se do pressuposto que o resultado do todo deve ser melhor que a soma das partes. Uma prática comum é a mudança de ordem nas apresentações assim como solicitação de retiradas de membros da equipe podendo chegar até mesmo à exposição individual. Uma premissa básica é que um deve ser capaz de apresentar por todos em todas as fases considerando o seu envolvimento integral no processo. 


\subsubsection{Conversas individuais e coletivas}

Importante para o desenvolvimento dos estudantes atua-se, no plano individual e coletivo, com conversas visando o desenvolvimento pessoal, técnico e profissional com o professor sendo o mediador.

Figura 6: Abordagem para repasse de conhecimento

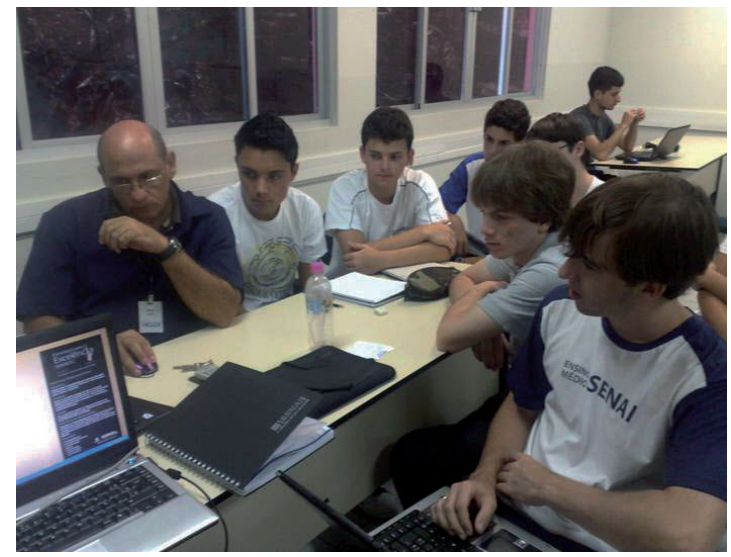

Fonte: Dos autores

Nessa imagem, pode-se observar uma das situações em que os estudantes dialogam sobre um novo conhecimento, para que possam aplicá-lo em seus trabalhos. Neste caso, a reunião aconteceu com membros de equipes distintas, que estavam no mesmo estágio de desenvolvimento do processo e necessitavam da mesma informação para prosseguir com seus trabalhos, mas essa ação também pode ocorrer individualmente ou com membros de apenas uma equipe.

Figura 7: Incursões dos professores em situações pontuais

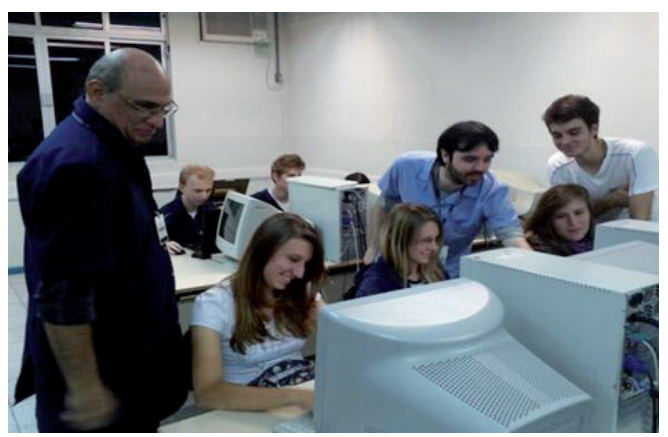

Fonte: Dos autores 
A figura acima mostra um momento onde os estudantes necessitaram de um auxílio mais direto dos professores, pois seus softwares estavam com falhas na programação. Nessas ocasiões, se "encaixam" momentos de resolução de problemas ou dúvidas pontuais, onde os estudantes encontraram alguma dificuldade.

Figura 8: Reunião de equipe

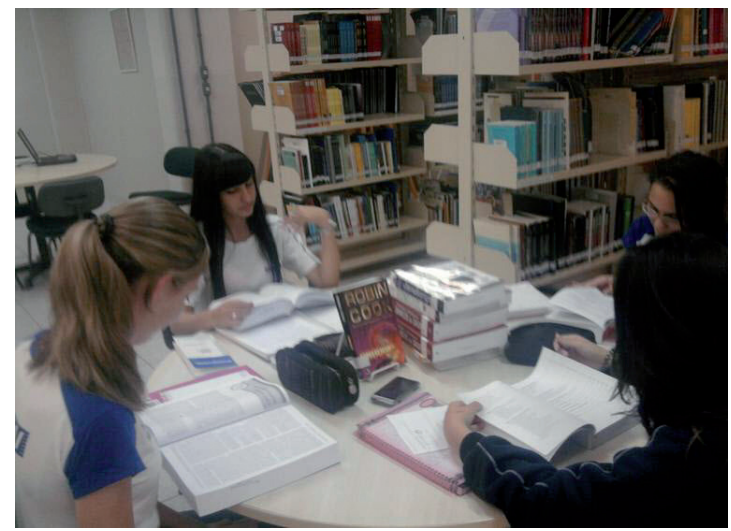

Fonte: Dos autores

Reuniões como a vista na figura acima podem ocorrer a qualquer momento, conforme a necessidade dos estudantes seja para a realização de pesquisas tendo como objetivo a fundamentação teórica do trabalho; para discussão de ações ou situações momentâneas do processo; para o desenvolvimento ou verificação do cronograma da semana, ou outras situações pertinentes, aumentando também a sinergia entre os membros da equipe. Essas reuniões não necessariamente precisam ocorrer em sala. A reunião acima, por exemplo, foi realizada na biblioteca da instituição, onde pela necessidade dos estudantes, de utilizar livros para sua fundamentação teórica, a equipe acreditou ser o ambiente ideal, pela facilidade de acesso aos conteúdos.

\subsubsection{Acompanhamento nas entrevistas de projeto}

Promove-se a integração entre teoria e prática a partir da elaboração de projetos para clientes reais. Estes projetos, por sua vez, são construídos segundo metodologia de desenvolvimento própria. Essa requer que os estudantes estejam em constante contato com os clientes fazendo com que este participe ativamente da construção do projeto. Nesses momentos os professores mediadores atuam efetivamente supervisionando o processo a fim de conhecê-lo com maior propriedade para que possa auxiliar em futuras orientações e/ou incursões. 


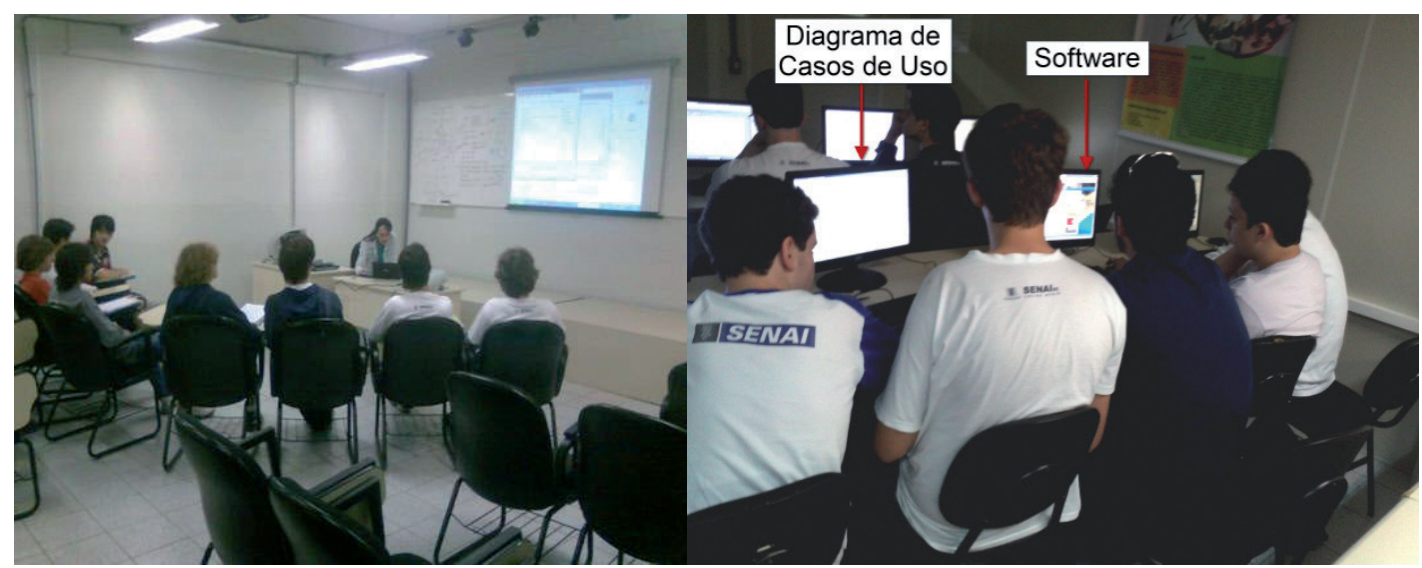

Fonte: Dos autores

A imagem à esquerda mostra uma reunião com o cliente de duas equipes, que estavam desenvolvendo projetos complementares para atender a duas necessidades, distintas mas integradas, do mesmo. É nessa situação que os estudantes têm a chance de vivenciar o contato direto com o cliente que Ihes solicitou o software, conhecendo melhor o problema que causou a necessidade para atendê-lo com mais proficiência. A imagem da direita mostra os estudantes discutindo com o cliente a estrutura do software mostrando o design gráfico e o diagrama de caso de uso, um artefato para o desenvolvimento de softwares. Observa-se nesse caso, a relação entre o produto e seu projeto.

O contato com o cliente pode ser marcado pelo mesmo ou pelos estudantes, conforme necessidade de uma das partes, seja na instituição de ensino na empresa dele ou em outro local combinado, a qualquer momento, inclusive em horários extraclasse quando for necessário. Pode-se usar também os meios eletrônicos para a resolução das dúvidas mais simples. Nas primeiras entrevistas, há sempre o auxílio de algum dos professores, até para transmitir mais confiança ao cliente, tendo em vista que os desenvolvedores do projeto serão, na visão inicial do cliente, jovens sem experiência na criação de software, mas no momento em que o mesmo percebe o nível de seriedade do trabalho, certas reuniões ocorrem apenas entre cliente e equipe.

\subsubsection{Trocas de experiências}

Em um ambiente onde se constrói conhecimento, seja qual for sua natureza, é importante estimular a troca de experiência para que o processo torne-se mais produtivo. Neste contexto, incentiva-se que durante o desenvolvimento das atividades, a prática de conversa informal dentro ou fora do ambiente de trabalho, seja pessoalmente ou online, para que os estudantes estejam interagindo sobre, problemas encontrados, soluções aplicadas, tecnologias, comportamento pessoal e/ou profissional. 


\subsubsection{Cronograma de atividades}

A partir do momento em que considera-se que os estudantes estão "amadurecidos" do ponto de vista, pessoal, técnico e profissional no processo como um todo, orienta-se a elaboração e utilização de cronograma de atividades para a gestão dos seus projetos objetivando com isto que comecem a perceber a idéia de produção e produtividade, responsabilidade, cobrança e compromisso. O acompanhamento do cronograma é semanal, no primeiro dia de aula da semana, a equipe se reúne para a discussão das tarefas e no último, discute-se o resultado das ações da semana.

\subsubsection{Café pedagógico}

Na existência de questões individuais específicas, comportamental ou intelectual, positivas ou negativas, um professor pode chamar o estudante para tomar um "cafezinho" na sala dos professores para a troca de informações sobre o andamento do processo, atitudes individuais ou do grupo de estudantes, pareceres sobre problemas ou melhorias que podem ser aplicadas.

\subsubsection{Maratonas de programação}

As maratonas de programação surgiram da necessidade de viabilizar para o estudante um tempo maior e com melhor qualidade para que possam desenvolver os programas de seu projeto quando da fase de implementação. Estes momentos normalmente acontecem aos sábados, com a participação dos professores mediadores para quaisquer esclarecimentos e/ou orientações que se façam necessárias. Estimula-se também a troca de informações entre diferentes equipes.

\subsubsection{Orientações TCC}

São realizadas continuamente com as equipes de trabalho nos contextos de orientação da escrita e construção, como também, orientação técnica dos temas abordados no TCC. Estas ocorrem durante a semana ou podem também ocorrer aos sábados.

\subsubsection{Banca de apresentação final de TCC}

A banca de apresentação de TCC, ilustrada pela figura a seguir, é quando formalmente se apresenta o software desenvolvido e suas bases teóricas. 
Figura 10: Banca de apresentação de TCC

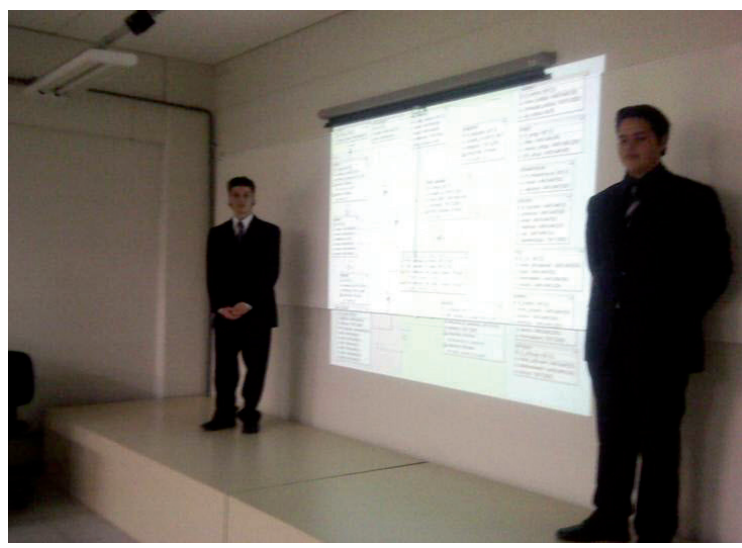

Fonte: Dos autores

A banca é composta por três pessoas ou mais, sendo no mínimo dois professores e, sempre que possível, o próprio cliente do projeto. Nesse momento, os alunos já estão acostumados a se apresentar em público, e por já terem defendido previamente os mesmos conteúdos aos professores nas Pré-bancas, eles se sentem muito mais seguros e confiantes. No caso da imagem acima, os próprios integrantes da equipe decidiram pela roupa mais social para passar, segundo os próprios, "mais confiança", mas não é algo obrigatório.

\subsection{Características das avaliações}

Os métodos desenvolvidos permitem a avaliação do conhecimento, por parte de professores e estudantes, sem a necessidade do uso de provas ou testes. A todo o momento os estudantes fazem uso dos conhecimentos característicos de cada fase do desenvolvimento e devem "validar" e discutir os dados com uso de comunicação oral e escrita. Questionamentos, observações e anotações por parte dos professores servem como indicação para avaliação que é discutida no grupo de professores e socializada com os estudantes apontando aspectos positivos e oportunidades de melhoria. Destarte, pode-se considerar que o método avaliativo apresenta como características o fato de ser sistêmica, individualizada, qualitativa, contínua. Essas questões serão brevemente apresentadas.

É sistêmica: Considera-se que o estudante deve agregar o conhecimento do todo e também poder interferir a qualquer momento na construção e desenvolvimento, de projetos, de programas de computador, de trabalho em equipe, da gestão de problemas, de pesquisa e utilização de novas tecnologias. São avaliadas o desempenho dos estudantes a partir dos pontos de checagem, mencionados anteriormente, podendo estes serem durante ou término de atividades técnicas sugeridas e/ou desenvolvimento ou término das fases do projeto. 
É individualizada: Acompanhamento diário e individualizado do desempenho do estudante quanto ao seu desenvolvimento técnico em projeto de software e programação de computador a partir de feedback das atividades sugeridas. Este também ocorre nos pontos de checagem durante e ao término das fases do projeto.

Respeita o tempo: Neste contexto procura-se respeitar o tempo em que cada estudante se apropria dos conhecimentos para que possam desenvolver-se bem no curso e no mercado de trabalho. Os conhecimentos dos quais citamos seguem indicadores mínimos exigidos pelo currículo do curso e mercado de trabalho aos quais os estudantes devem persegui-los podendo estes alcançá-los minimamente ou ultrapassá-los, mas, ao seu tempo.

É qualitativa: As avaliações baseiam-se nos conhecimentos, habilidades e atitudes apreendidas visando, com a agregação destes, o desenvolvimento das atividades propostas. Não existe a preocupação com nota, mas sim com conhecimento agregado. Caso o estudante não o tenha ainda alcançado, parte-se para ações, no contexto das atividades avaliadas, para que os agregue afim de que possa prosseguir no seu desenvolvimento.

É contínua: Em virtude do processo ser sistêmico o estudante é avaliado constantemente pois sempre estará no ciclo de agregação de conhecimento, sanando suas dúvidas, solucionando problemas e produzindo resultados, incessantemente. A monitoração permite aos professores mediadores a avaliação contínua com base na evolução das atividades desenvolvidas.

Figura 11: Acompanhamento das equipes

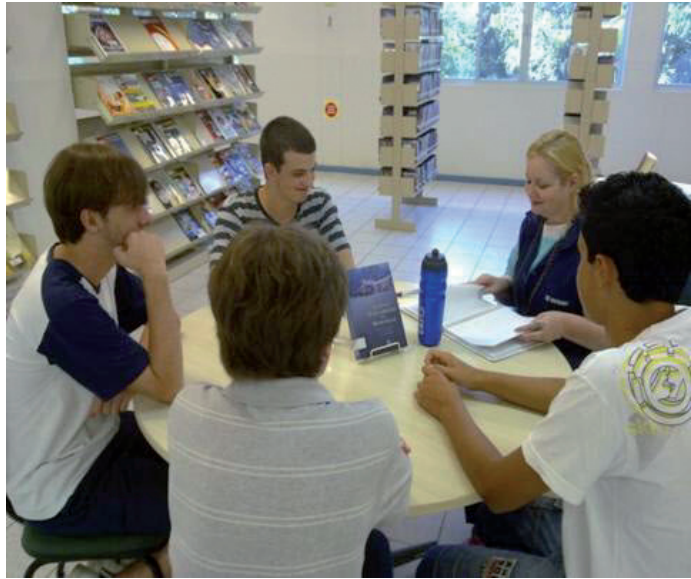

Fonte: Dos autores 
Como a figura acima ilustra, em certos momentos se faz necessário um acompanhamento do desenvolvimento das equipes, para que seus integrantes deixem os professores a par do andamento de seus trabalhos. Nesse acompanhamento, pode-se fazer algum Ponto de Checagem, verificar o andamento do cronograma, tirar possíveis dúvidas e tomar decisões sobre o desenvolvimento das atividades.

\subsection{Resultados a partir de relato dos estudantes e ex-estudantes}

O resultado positivo tem sido perceptível ao longo dos últimos cinco anos, observase que os estudantes estão mais preparados ao final do curso para iniciar a carreira profissional. A qualidade dos TCCs que era um problema inicial melhorou e apresenta na atualidade características que surpreendem até mesmo os empregadores como pode ser observado na fala de um ex-aluno.

\footnotetext{
"Boa noite professor, Hoje realizei a minha primeira entrevista de emprego, na (empresa). Creio que fui bem. Acho que os entrevistadores (pelo menos da parte técnica) ficaram surpresos com o que foi trabalhado no TCC, acho que até um pouco desconfiados haha. E é bem isso que eles estão interessados, em profissionais com conhecimento em PHP, JavaScript e SQL!" (informação verbal). ${ }^{1}$
}

Da mesma forma, as aprovações em 2011 chegaram a 100\% assim como reduziu o índice de evasão que destaca-se entre os mais baixos da instituição. Para melhor caracterizar os resultados são apresentadas algumas opiniões dos estudantes que participaram do projeto no ano de 2011 e de ex-estudantes.

Referente ao processo ser diferente do comumente vivenciado durante a vida escolar dos entrevistados, eles observam que uma visão sistêmica é relevante para a apreensão do conhecimento.

\footnotetext{
"Muito superior ao modelo tradicional, principalmente por proporcionar com que o conhecimento evolua de acordo com a atual situação do aluno, impedindo a passagem de conteúdos incompreendidos. Mesmo porque na programação um assunto depende do outro, sendo imprescindível a compreensão de todas as etapas." (informação verbal). ${ }^{2}$
}

Rodapé 1 a 7: Relato dos entrevistados (alunos e ou professores), concedido em SC, 2012.

O fato de ser direcionado e contínuo possibilita a melhor compreensão, assim como torna o processo mais dinâmico a partir do momento que os estudantes se sentem como agentes responsáveis pelos seus resultados.

\footnotetext{
"Muito bom, dessa forma fica mais fácil aprender já que o professor concentra suas explicações em grupos menores nos dando mais atenção. Além disso, não é tão cansativo e nos traz responsabilidades em relação a prazos." (informação verbal) ${ }^{3}$.
} 
O processo de mudança de atitudes não se constrói de forma abrupta. Os estudantes passam a lidar com uma "liberdade" até então não vivenciada, há autonomia total para transitar por todas as partes da instituição, salas de aula, biblioteca, laboratório e qualquer espaço que acharem pertinente para o desenvolvimento do trabalho. Saber lidar com essa liberdade é o desafio por parte dos estudantes e exercício de percepção por parte dos professores para indicar as melhores práticas. Isso, porque ao mesmo tempo que os estudantes tem a liberdade, passam a ser responsáveis pelos seus atos. Esse "antagonismo" característico de situações complexas pode ser observado na fala de um dos entrevistados.

\title{
"É muito liberal", "alguns alunos se sentem pressionados". (informação verbal) ${ }^{4}$.
}

Ao perceberem que fazem parte de um processo diferenciado, alguns levam um tempo maior para ter essa percepção, cria-se vínculos de confiança entre professores e estudantes e de valorização do processo. A fala a seguir é de um ex-estudante que na atualidade apóia a atividade de contratação de profissionais na empresa em que trabalha.

\begin{abstract}
"Oi professor.. tudo bom? Temos aqui na empresa algumas vagas de estágio.. você não tem alguns alunos que estão se formando esse ano no técnico do SENAI ou que se formaram ano passado pra indicar? Mas passa os melhores, os mais esforçados. Temos vagas para programador Java pra pessoas com mais experiência também.. se tiver alguém para indicar eu agradeço." (informação verbal) $)^{5}$.
\end{abstract}

Outro fator primordial é o fato de "se saber porque se está fazendo" e estar apto para lidar com outras situações. O objetivo final é indicar que se está pronto para iniciar no mundo do trabalho, no entanto, o bom profissional é aquele que tem consciência de que "sempre pode melhorar". Essa questão pode ser observada na fala de um ex-estudante.

\footnotetext{
"Olá professor queria pedir para o senhor me sanar uma dúvida sobre um passo na minha careira como programador. Eu escolhi em não fazer um curso superior voltado a desenvolvimento e análise de softwares, pois achei (erroneamente) que era quase possível ficar naquela de PHP estruturado com html(zinho) e CSS, mas ultimamente tenho dado uma pesquisada sobre empregos em Joinville relacionados a desenvolvimento de software e percebi que grande parte pede algum curso superior tanto completo como em andamento na área de softwares, e também que há outras linguagens que são muito procuradas como JAVA, Delphi, e Progress. Li um pouco sobre JAVA e Progress, sendo respectivamente Orientada e Estruturada. Ai vem minha "grande" pergunta, atualmente estou lendo e praticando JAVA, vi que ela é uma linguagem muito grande em relação aos seus usos como para WEB e para portáteis, estou bem no começo mesmo usando o netbeans para praticar, então gostaria de saber se vale a pena eu continuar o estudo por ela em casa como estou fazendo seguindo os passos e lições deste site, ou se é melhor partir para outra linguagem como Progress, ou até mesmo mudar a forma de estudo fazendo algum curso na região? Desculpe-me por atrapalhar suas férias, mas preciso desse macete(zinho). Obrigado e abraços." (informação verbal) ${ }^{6}$.
} 
Observa-se que repetidas vezes utilizou-se a palavra processo. Isso porque a sua valorização é primordial na concepção teórica e metodológica do projeto. A construção de conhecimento se dá pela relação e interação entre os agentes do processo ensino e aprendizagem. Primordial é a participação do cliente real para que os estudantes se percebam como capazes de se transformarem e de transformar uma realidade. O produto final, que é o software é a consequência desse processo e retribuição ao agente externo envolvido que é cliente. Segue a fala de um dos clientes envolvidos:

\footnotetext{
"Devido a alta demanda de serviços e necessidade de uma maior agilidade entre o planejamento e execução, o software desenvolvido pela equipe de alunos do SENAI, foi um grande diferencial para a melhoria e organização do planejamento $x$ execução, dentro da ferramentaria aplicada, possibilitando um maior domínio das atividades e rápido feedback das atividades em processo." (informação verbal)7.
}

Há de se mencionar que alguns dos softwares não chegam a ser publicados por conta de questões econômicas e de estratégias definidas pelo próprio cliente, proprietário do software, mas o significado do produto é dado ao conhecimento adquirido pelos envolvidos no processo.

\section{CONSIDERAÇÕES FINAIS}

O objetivo do relato foi mostrar algumas práticas que foram se constituindo no Projeto Escola Sistêmica do Curso Técnico em Informática de Joinville nos últimos cinco anos. Uma das metas que motivaram o relato foi de mostrar práticas aplicáveis em outras situações de aprendizagem. No entanto, há de se mencionar mesmo que os resultados sejam positivos, que o processo de construção se dá em ambientes de conflito que são próprios para a construção do conhecimento. As práticas apresentadas são mutáveis diante do dinamismo da abordagem. Da mesma forma, muitos foram os erros cometidos até se chegar à um modelo, nunca ideal, mas de referência. De outra maneira, também é pertinente considerar que um dos fatores motivadores da continuidade do projeto é a melhoria contínua do processo. Uma fala usual é, "não sabemos o certo, já sabemos muitas coisas erradas porque erramos muito, mas mesmo assim, estamos melhorando a cada dia."

Um projeto com essa característica exige uma constante autocrítica por parte dos docentes assim como uma pré-disposição a trabalhar de forma diferente do habitual. A instabilidade é própria em um sistema que está em constante auto-regulação. Essa interpretação é vivenciada na prática pelos professores do projeto. Da mesma forma, não se esqueceu que o processo envolve seres humanos em transformação e todos os métodos hoje validados foram se constituindo de maneira "controlada" para não fazer "experiências" com as expectativas e anseios dos estudantes envolvidos. Esse público já nasceu em um mundo interconectado e interativo em que a estrutura educacional 
no país ainda não está adequada. Aulas tidas como tradicionais já na década de 1970, como foi observado no texto, atendem de forma incompleta à realidade de mundo dos adolescentes atuais.

\title{
SYSTEMIC SCHOOL: A REPORT OF PRAXIS IN SENAI JOINVILLE-SC
}

\begin{abstract}
This report aims at showing some methods of project called Systemic School, held last year in a Technical Course in Computing at SENAI Joinville - SC. The project presents a process of teaching and learning with interdisciplinary pathways characteristic of transdisciplinarity. As a proposal, this article listed the main methods aligned to show how to approach the practice with some results observed by students and teachers. This paper presents an account of the experiences of the past five school years. For this, we used the research participant considering the authors' experience as teachers. As evidence nondirective interviews were applied to indicate the perception of the students involved in the project in 2011. We also considered the opinion of former students who still keeps in touch with teachers. As a result it should be noted the current understanding of the method and its results. These, in turn, to be dealing with a systemic approach consider constructions with levels of complexity in constant transformation.
\end{abstract}

Keywords: Systemic School. Technical Course in Computing. Teaching and learning process. 


\section{REFERÊNCIAS}

AMBONI, Nério et al. Interdisciplinaridade e complexidade no curso de graduação em Administração. Cad. EBAPE.BR [online], Rio de Janeiro, v.10, n.2, artigo 4, p.302-328, 2012.

DA SILVA, Roberto; CERVO, Amado L.; BERVIAN, Pedro A. Metodologia científica. 6. ed. São Paulo: Pearson Prentice Hall, 2007.

ESLABÃO, Leomar da Costa. A construção de um currículo por competências: o caso do Curso técnico em sistemas de telecomunicações do CEFET-RS. 2006. 226 f. Dissertação (Mestrado Educação)- Universidade Federal de Pelotas, Pelotas, 2006.

LAVAQUI, Vanderlei; BATISTA, Irinéa de Lourdes. Interdisciplinaridade em ensino de ciências e de matemática no ensino médio. Ciênc. educ. (Bauru), Bauru, v. 13, n. 3, p.399-420, dez. 2007.

MANGINI, Fernanda Nunes da Rosa; MIOTO, Regina Célia Tamaso. A interdisciplinaridade na sua interface com o mundo do trabalho. Rev. katálysis [online], Florianópolis, v.12, n.2, p.207-215, 2009.

MAGALHÃES, Gildo. Introdução à metodologia da pesquisa: caminhos da ciência e tecnologia. São Paulo: Ática, 2005.

NAGEL, Thomas S.; RICHMAN, Paul T. Ensino para competência: uma estratégia para eliminar fracasso. Porto Alegre: Globo, 1976.

NUNES, Simone Costa. A inserção da noção de competências em cursos de graduação em administração. 2007. 438 f. Tese (Doutorado em Administração)-Faculdade de Ciências Econômicas da Universidade Federal de Minas Gerais, Belo Horizonte, 2007.

SEVERINO, Antônio Joaquim. Metodologia do trabalho científico. 23. ed. São Paulo: Cortez, 2007.

TONSIG, Sérgio Luiz. Engenharia de software: análise e projeto de sistemas. 2. ed. São Paulo: Ciência Moderna, 2008.

VASCONCELLOS, Maria José Esteves de. Pensamento sistêmico: o novo paradigma da ciência. Campinas: Papirus, 2002.

ZARIFIAN, Philippe. Objetivo competência: por uma nova lógica. São Paulo: Atlas, 2001. 


\section{SOBRE OS AUTORES}
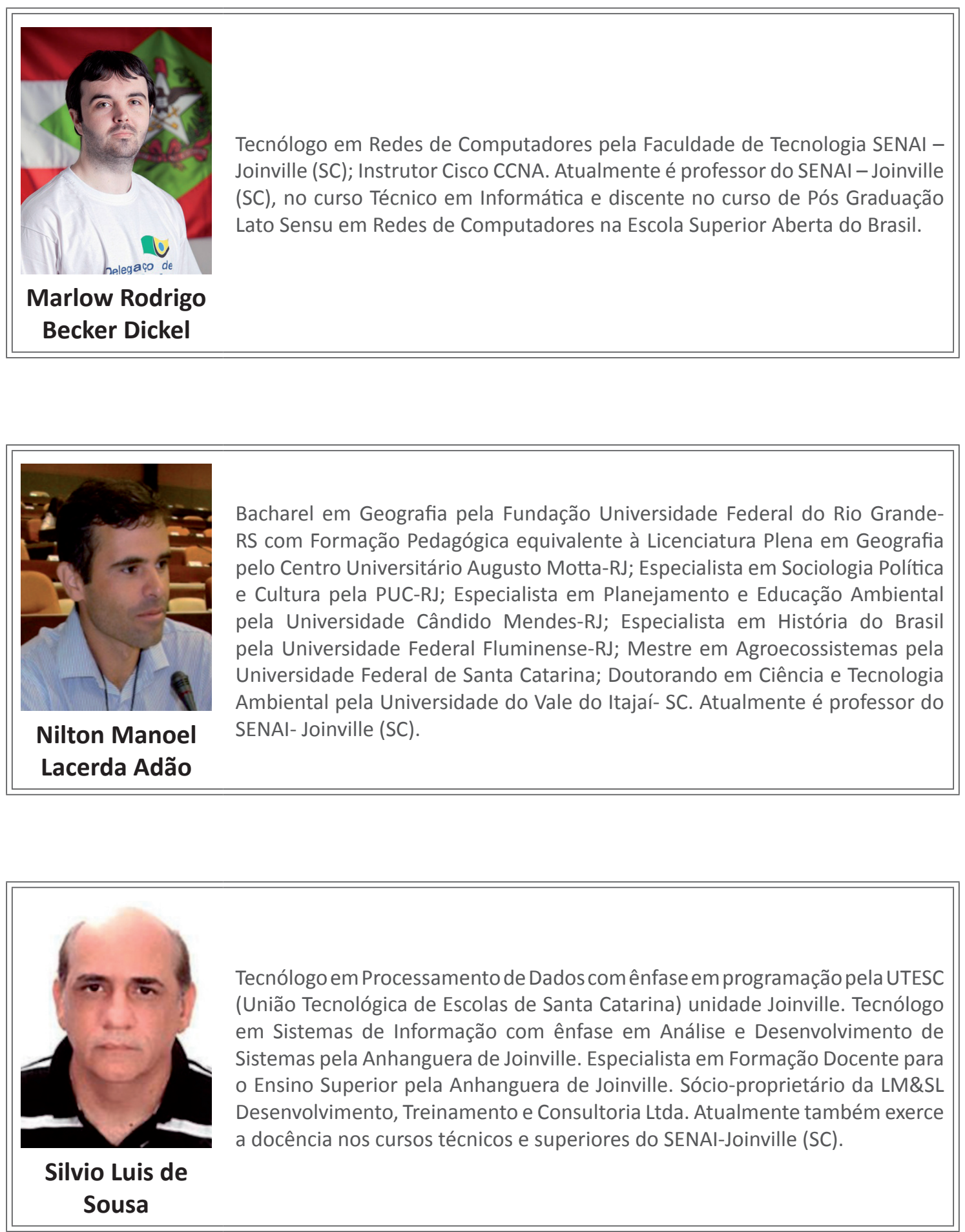